\title{
Limites à Condenação do Aborto Seletivo: a De- ficiência em Contextos de Países Periféricos
}

ALESSANDRA BARROS ${ }^{l}$

\section{RESUMO}

Este artigo analisa a opinião apresentada por Adrienne Asch em "Diagnóstico pré-natal e aborto seletivo", presente na coletânea deste mesmo volume da Revista Physis. A posição de Asch, acerca do caráter discriminatório do aborto seletivo, será apreciada a partir da qualidade de sua retórica argumentativa. Em seguida, será revista à luz da realidade sociocultural do Brasil, país periférico, caracterizado, para fins de comparação com os Estados Unidos, como país de legislação proibitiva para o aborto, de incipiente mobilização política organizada das pessoas deficientes e no qual a história de doutrinas e práticas eugênicas percorreu outras trajetórias.

Palavras-Chave: Aborto seletivo; deficiência; diagnóstico pré-natal. 


\section{Retomando os Argumentos da Autora}

A posição sustentada por Adrienne Asch sobre o aborto seletivo é clara e objetiva: é uma prática temerária que atenta contra os interesses das pessoas deficientes, na medida em que sinaliza aos deficientes vivendo em sociedade que sua presença não é bem-vinda, devendo assim, se possível, ser evitada por ocasião da concepção de um feto com anomalias. O argumento de Asch é, na verdade, uma reedição e reelaboração das posições comungadas por um grande número de filósofos, acadêmicos e ativistas, principalmente estadunidenses (Buchanan, 1996; Saxton, 2000; Kaplan, 1994; Field, 1993). A novidade, todavia, é a síntese e a incorporação da questão da informação veiculada por ocasião dos diagnósticos que antecipam o aborto seletivo. Segundo Asch, o teor da informação que permeia os momentos de aconselhamento pré-natal seria igualmente discriminatório, pois que, em essência, é tendenciosa ao assumir uma perspectiva amplamente pessimista na forma como descreve a vida das pessoas deficientes.

Para Asch, uma apresentação mais positiva da deficiência, ou ao menos mais justa, seria aquela que privilegiasse sua descrição a partir do modelo social da deficiência, modelo que contrasta com a descrição corrente clínica ou biomédica - comumente veiculada pelos profissionais de saúde nas sessões de aconselhamento genético. Segundo o modelo social da deficiência, viver como uma pessoa deficiente pareceria tão difícil, não devido a circunstâncias imanentes à lesão em si, mas em grande medida devido às condições impostas por uma sociedade que não favorece a adaptação daqueles que não preenchem os parâmetros de normalidade.

Neste sentido, a postura de Asch em relação ao aborto seletivo não reside na forma de um absoluto desagravo: ela prefere postar-se como favorável à autonomia reprodutiva da mulher ou do casal, sendo portanto, pró-escolha. Assim sendo, as pessoas teriam todo o direito de optar pelo aborto seletivo, desde que, por ocasião do diagnóstico pré-natal, fossem devidamente - ou mais positivamente - informadas sobre o que representa viver com uma deficiência e sobre o que representa criar uma criança com deficiência. Nos próprios termos de Asch, isso significaria ser instruído sobre a deficiência de uma forma desvinculada da perspectiva biomédica.

No entanto, esse aspecto-chave de sua argumentação, que faz parecer que tudo dependeria da qualidade da informação que instrui os momentos do diagnóstico pré-natal, fundamenta-se em uma aposta desmedida e exagerada do poder da palavra sobre as representações e destas sobre as práticas. A 
autora não considera que os valores que informam as condutas dos profissionais de saúde e que derivariam nas opiniões acerca da deficiência desdobradas aos pais, são, antes de tudo, representações sociais forjadas na complexidade de uma dialética que transcende a influência até mesmo de grandes campanhas informativas das políticas públicas em saúde.

Os demais questionamentos a serem feitos acerca da posição defendida por Asch resultam de problemas inerentes à sustentabilidade do modelo social da deficiência, que, nos termos retomados por aquela autora, se fazem denunciar por sua própria retórica argumentativa ${ }^{2}$. Desse modo, no curso do encadeamento lógico de sua posição, ela descreve a deficiência de maneira eufemizada. Não considera grandes incapacitados, deficiências múltiplas e síndromes severas, como a de Lech-Nyham, Patau e outras. Faz uma opção disfarçada por aqueles quadros de deficiência ou doenças crônicas mais facilmente passíveis de adaptação ao convívio social: como a síndrome de Down, a fibrose cística, a diabetes ou a anemia falciforme. Do mesmo modo, omite a dramaticidade dos quadros de deficiência e doenças progressivas que levam à morte e, da única vez no artigo em que assume a concretude das dores físicas experimentadas por essas formas extremas (mas não raras) de sofrimento, apenas as menciona, para, em seguida, centrar-se na questão da dor social causada pelo isolamento e pela discriminação, enquanto produtos de uma sociedade excludente.

A fragilidade de seu arranjo argumentativo fica exposta, por outro lado, quando busca sustentar a postura pró-escolha em arremate aos desagravos emitidos pelo aborto seletivo e pela informação enviesada dos diagnósticos pré-natais. O apelo constante a estatísticas que mostrem como há famílias ou casais realizados e felizes com seus filhos deficientes não parece recurso compatível com a afirmação das liberdades individuais - próprio de posturas pró-escolha - tal como é feito pela autora. Para ser coerente com o reconhecimento do livre direito de escolha, há de se considerar que, mesmo que haja apenas uma família, casal ou mulher insatisfeitos com a idéia de ter um filho deficiente, em meio a milhares que se dizem satisfeitos, aquela condição de insatisfação é legítima, pode ser reclamada e utilizada para justificar a opção pelo aborto seletivo, que, no final das contas, viria a tratar da expressão de sua autonomia reprodutiva.

A falta de consistência da postura pró-escolha, que a autora subscreve, fica evidenciada também pelo modo como a mesma se situa em relação ao aborto, colocado em temos genéricos, ou seja, independentemente de um recorte específico. Desta vez, mais sutilmente, é detectável uma inclinação 
da autora, a julgar uma certa imoralidade na prática do aborto, quando, por exemplo, ao comparar o aborto seletivo a outras formas de prevenção de deficiências, parece dar ao feto, no modo como se expressa, o mesmo status de pessoa. Logo, abortar um feto com deficiência seria o equivalente quase imediato de abortar uma pessoa com deficiência. Tal deslize semântico, longe de demonstrar um descuido de sua narrativa, representa, talvez, a denúncia do posicionamento subliminar da autora, situado em uma zona de dubiedade própria do tipo de reflexão que não opera verdadeiramente com o caráter socialmente construído de conceitos tidos como dados a priori, tais quais a infância ou a maternidade. Deste modo, é fácil identificar recurso semelhante, quando a autora discorre sobre a dificuldade dos profissionais de saúde e dos futuros pais, não familiarizados com a deficiência, em enxergar a criança que existiria naquele indivíduo deficiente, para além das lesões que ele porta. Pois, ao tratar dessa entidade - "criança" ou "infância" enquanto eclipsada pela deficiência, parece haver um apelo tácito àquelas categorias enquanto condições naturalizadas e não socialmente construídas.

Esse resvalar para um tratamento reificador de categorias que seriam mais bem apreendidas como construtos sociais é também percebido no modo como a autora se apropria da noção de sociedade. Permeando seu discurso como um todo, esse aspecto parece, na verdade, um subproduto da insuficiência da operacionalização do modelo social de deficiência. Ao transitar do corpo biológico para o corpo social, no sentido de localizar no segundo as disfunções que causariam a rejeição às pessoas deficientes, o modelo social da deficiência acaba por impingir um caráter monolítico à sociedade, culpabilizada pela condição de exclusão e opressão às pessoas deficientes. Tanto assim o é que, caso se viesse a realizar o exercício especulativo de elaborar uma mesma reflexão sobre o aborto seletivo que, no entanto, partisse de exemplos, estatísticas, suportes teóricos e todo um conjunto de representações próprio de outra sociedade e realidade sociocultural, o resultado não pareceria tão universalizável quanto a prescrição ética de Asch fez parecer.

Deste modo, se tomarmos o contexto brasileiro como contraponto à realidade estadunidense, de onde partiram as reflexões da autora em pauta de crítica, teremos um outro cenário de conjunturas sócio-históricas. Deste cenário destacamos, para os fins do presente artigo, dois aspectos: a nossa trajetória peculiar de constituição de doutrinas e práticas eugênicas oficiais e a imaturidade da mobilização civil organizada em torno dos interesses dos deficientes, que não autoriza a categoria a falar, numa perspectiva sociopolítica, 
de um movimento de deficientes.

\section{Eugenia à Brasileira}

Dado o caráter de seleção seguido de eliminação, presente no aborto por anomalia fetal, e dada sua realização no âmbito da reprodução humana, tal prática pode ser estreitamente associada à eugenia - doutrina de pretensões científicas que propugnava a melhoria da espécie humana através da seleção artificial de indivíduos considerados mais adequados. Essa seleção se daria ou pelo favorecimento à reprodução daqueles tidos como melhores, ou pelo impedimento à reprodução dos tidos como insatisfatórios, segundo os parâmetros elegidos. $\mathrm{O}$ escopo abrangido pelo impedimento à reprodução compreenderia tanto a esterilização quanto o aborto e, em casos extremos, até mesmo o infanticídio. Uma vez que a eleição dos tipos indesejados não era aleatória, mas sempre circunscrita a uma categoria de pessoas, e dado que a condição de sujeição a tal imposição era que esta categoria não expressasse representatividade política, minorias étnicas e raciais foram aquelas tradicionalmente submetidas a práticas eugênicas.

Este preâmbulo propositalmente amplo, acerca da eugenia, serve, antes de tudo, para, destacando a compreensão hegemônica que se tem de tal doutrina, remetê-la ao substrato da argumentação de Asch quando esta tratou da questão do aborto seletivo. Ainda que não explicitamente situadas, tanto a sua, quanto a maioria das contestações emitidas contra o aborto seletivo referem-se a preocupações fundadas nas conseqüências de históricas aplicações de doutrinas eugênicas. Mas o que raramente fica claro é que tal associação de aborto seletivo e eugenia só pode ser realizada inequivocamente, caso se tenha em conta apenas uma forma de expressão de práticas eugênicas - o que, em verdade, não se comprovou historicamente (Adams, 1990). Visto que uma medida discriminatória, perpetrada por uma doutrina eugênica, busca a justificação de sua eficácia em fundamentos científicos e a afirmação de sua necessidade como estratégia política, há de se considerar o quanto variam, de uma sociedade para outra, no tempo ou no espaço, os parâmetros que julgam a oficialidade da ciência e as prioridades das políticas de um Estado.

Sendo assim, o que se tem, quando se comparam as expressões da eugenia nos Estados Unidos e no Brasil, numa mesma época, é a constatação de linhas de aplicação e de legitimação ideológica, significativamente diversas. Enquanto a eugenia propalada e praticada nos Estados Unidos, nas 
primeiras décadas do século XX, era fortemente segregacionista e intransigentemente racista, a eugenia brasileira, naquele mesmo período, estava fortemente associada a questões de saneamento ambiental e saúde pública (Stepan, 1990). Enquanto a eugenia estadunidense requeria a proibição radical de casamentos inter-raciais, a brasileira preocupava-se muito mais em promover exames médicos pré-nupciais que detectassem principalmente doenças venéreas ou o abuso de álcool, que, segundo se acreditava, se transmitidos à prole degenerariam toda a descendência do casal. Muito embora a eugenia brasileira também aventasse a possibilidade de interdição da procriação de indivíduos com lesões físicas e/ou mentais, criminosos e prostitutas, a tradição fortemente católica sempre impediu que tal medida vicejasse, e seus defensores, alguns ferrenhos, nunca alcançaram reconhecimento unânime.

Comparar orientações eugênicas díspares passa por identificar as motivações políticas de cada sociedade. Assim, embora o que se tenha em comum seja a busca de formas de projeção nacionalista e de afirmação da identidade nacional, o modo como cada nação diagnostica seus problemas e as prioridades para o alcance daqueles objetivos é que pode resultar em formas distintas de expressão de doutrinas eugênicas. A eugenia nazista, por exemplo - que, embora não tenha sido experimentada pelos Estados Unidos em sua vertente de extremismos, lhe serve de referência quando hoje se busca condenar práticas como o aborto seletivo - possui outras raízes explicativas ${ }^{3}$. Estas estariam referidas à importância da projeção da nação alemã, remontariam à expansão germânica, ao estabelecimento de fronteiras territoriais, à afirmação de uma língua e cultura sobre outra e à necessidade da imputação de culpa a um povo, pela falência econômica de um pósguerra.

Por outro lado, a eugenia brasileira, conquanto também motivada pela questão da projeção internacional da nação, requeria, para a correção da visão que se tinha do Brasil lá fora - país de doenças endêmicas, de calor tropical insalubre, vasto em área, mas incapaz de ocupá-la efetivamente, pouco industrializado e analfabeto - outro entendimento das finalidades da eugenia. Desse modo, essa variante do movimento eugênico mundial manteve-se predominantemente associada ao saneamento público (que combatia as doenças que minavam a saúde dos brasileiros), à medicina preventiva (que os vacinava contra outras tantas doenças), à vigilância sanitária da polícia médica, à higiene mental (que preconizava a reclusão de prostitutas, alcoólatras, mendigos e alienados), à puericultura e à saúde materno-infantil 
(que garantiriam o aumento das taxas de natalidade requeridas para a ocupação produtiva do território nacional). Criticava os pressupostos anglosaxões de degenerescência da mestiçagem e apostava, ingenuamente, ora num branqueamento progressivo e inexorável da população brasileira, ora no vigor do híbrido impuro, que, numericamente majoritário, não permitia a uma elite branca minoritária esperanças impalpáveis.

A fundamentação científica para tal expressão da eugenia haveria de ser compatível à sua justificação. Desse modo, diferentemente da eugenia disseminada nos Estados Unidos, que se baseava na concepção mendeliana da genética, a eugenia brasileira, e a latino-americana de modo geral, a exemplo da eugenia francesa, baseavam-se, por outro lado, na concepção neolamarckiana da genética (Stepan, 1991). Embora já se tratasse de uma concepção tecnicamente ultrapassada pelos cânones da época, a superposição de uma perspectiva genética por outra não foi tão imediata de modo a permitir espaço para sua apropriação pela ciência brasileira, então defasada dos avanços recentes e afastada da pesquisa de ponta. Além disso, a aplicabilidade das premissas lamarckistas de transmissão hereditária de caracteres adquiridos do meio ambiente servia bastante adequadamente às finalidades de reconstrução dos ideais nacionais, pois projetava um olhar não só para o ambiente natural (onde estariam os mosquitos vetores de epidemias), mas também para o ambiente social (espaço da pobreza, a desnutrição e o analfabetismo a serem combatidos). A eugenia brasileira, neolamarckiana e saneadora, era ainda congruente com a moralidade católica tradicional, o que a fazia ainda mais atraente. Reforçar o combate a doenças venéreas e ao abuso de bebidas alcoólicas era tanto transformar condições sociais quanto escolhas morais. Fortemente atrelados à fé católica, os esforços pela legalização do aborto, mesmo em casos excepcionais (ao que se poderia chamar de aborto seletivo) foram, a propósito, sucessivamente frustrados.

\section{Pode-se Falar em um "Movimento de Pessoas Deficientes" no Brasil?}

Para responder à questão sobre em que medida a atividade de entidades organizadas pelos interesses de pessoas deficientes e a mobilização de outros sujeitos sociais em torno da mesma causa se configura na forma de um movimento social, optou-se por caracterizar a atividade dessas entidades, no tocante à qualidade da assistência social prestada. Não sendo possível ava- 
liar o conjunto das entidades que atuam no Brasil em favor das pessoas deficientes, optou-se pelo recorte junto às APAEs (Associações de Pais e Amigos dos Excepcionais e às Associações de Síndrome de Down).

Essas federações de entidades são suficientemente representativas, pois compõem as comissões do Conselho Nacional dos Direitos das Pessoas Portadoras de Deficiência ${ }^{4}$. São entidades capazes de exercer pressão sobre legisladores e operadores do direito, bem como de serem formadoras de opinião junto à população brasileira. Além disso, cumprem um papel importante na articulação de valores e na construção das moralidades acerca de pautas de interesse da comunidade beneficiada, uma característica fundamental para a mobilização dos "novos movimentos sociais". Essas entidades possuem, ainda, décadas de atuação, de modo que, muito embora sua atividade se dedique apenas à deficiência mental, elas são referenciadas pelo senso comum de forma quase sinônima com os deficientes de modo genérico.

Ressalvadas as devidas considerações e peculiaridades existentes em meio às tantas entidades voltadas à atenção do deficiente, pode-se dizer que, em geral, o que as desqualifica enquanto formadoras de uma rede ou movimento social, no sentido estrito, é o fato de manterem um perfil tradicionalmente assistencialista, que se sobressai em relação à função promotora de cidadania anunciada ${ }^{5}$. O perfil assistencialista referido desdobra-se ainda em outras características, quais sejam: limitarem-se ao cumprimento da prestação de serviços e serem representativas apenas dos interesses particularistas e corporativos de seus associados. A vocação solidária e altruísta em que se baseiam seus serviços é acionada apenas para atender às famílias diretamente afetadas. A pouca expressividade do ativismo político pode ser entendida ainda pelo fato de que os quadros de pessoal das entidades beneficentes tradicionais, como as APAEs, são compostos por funcionários ou voluntários sem formação superior. Quando existe, esta é em grande medida referida às áreas de saúde e educação, o que em geral não os operacionaliza politicamente ${ }^{6}$.

Por serem herdeiras do modelo caritativo da filantropia religiosa, pode-se dizer que as entidades de assistência a deficientes apresentam dificuldades em imprimir, nas gestões administrativas, maior profissionalismo na captação de recursos, tratamento empresarial no compromisso com a transparência e com a publicização de seus resultados. Esse amadorismo as aproxima da informalidade com a qual se administram os espaços domésticos, espaços por excelência privados, e aponta ainda para as mesmas posturas próprias 
daquele domínio, o qual se acredita imune às interferências ou exigências da ordem pública. Expressões de confusão e promiscuidade entre as esferas pública e privada podem ser ainda descritas pelo fenômeno do clientelismo - tipo de relação, contudo, cuja natureza corrompida nem sempre é assim identificada pela tradição cultural brasileira.

O clientelismo pode ser descrito como uma relação de troca de favores, em geral políticos, por benefícios econômicos de variado escopo. Tendo o clientelismo se disseminado na tradição política brasileira, este acaba por transitar para além dos momentos de manifestação representativa da democracia - como a eleição de governantes - contaminando igualmente a dinâmica das trocas estabelecidas no nível da participação cidadã na sociedade civil organizada. Logo, a perspectiva de análise da cultura política também identificaria expressões de clientelismo quando, por exemplo, o público-alvo de uma entidade beneficente, a busca apenas para a prestação de serviços imediatos, como um mero cliente busca uma empresa, desobrigado de contribuir para o fortalecimento identitário da categoria por aquela entidade assistida.

Desde a emergência do Terceiro Setor, nas décadas de redemocratização do regime e de fortalecimento da sociedade civil brasileira, essas entidades vêm tentando transpor o caráter filantrópico de suas atividades. Deste modo, passaram a fazer parte das agendas dessas entidades beneficentes pautas como inclusão social do deficiente a partir do acesso ao ensino regular, empregabilidade, defesa ampla de direitos e promoção à vida independente, em substituição aos consagrados temas da assistência médica e terapêutica e da escolarização no ensino especial. Entretanto, o nível de engajamento participativo das entidades de deficientes e a qualidade emancipatória de suas ações pode ser verdadeiramente explicitado pela apreciação da manifestação dessas entidades junto aos canais de participação cidadã, bem como pela utilização de mecanismos institucionais e sociais com o mesmo fim. Quanto a esses mecanismos,

"alguns foram institucionalizados a partir de propostas da sociedade civil (...), outros resultam das práticas dos movimentos e seu uso depende da conjuntura, da interlocução entre as diversas forças sociais, e da relação com o Estado (...)" (Teixeira, 2001, p. 173).

Tais mecanismos de participação são basicamente mecanismos de expressão do controle social nas tomadas de decisão. Podem ser do tipo administrativo, parlamentares e judiciais. São usados para cobrar a respon- 
sabilidade de autoridades, identificar erros, omissões e fraudes, opinar na propositura de projetos de lei, dentre outras finalidades. No tocante a esta última, por exemplo, a via imediata de intervenção se daria na forma de acompanhamento, por parte de representantes de entidades de deficientes, de sessões parlamentares ou audiências públicas, para as quais, nesses casos, bastaria a inscrição prévia para acesso às tribunas das Câmaras. Para além desses mecanismos formalmente instituídos, consideram-se ainda outros tipos de instrumentos político-sociais de participação cidadã, como, por exemplo, a publicização de moções, cartas-abertas, manifestos etc., através do uso da mídia, ou o advocacy dos ideais da entidade pela inserção de notícias na grande imprensa (Teixeira, 2001, p. 191).

Não obstante, para o contexto brasileiro como um todo, os índices de participação política e investimento colaborativo sejam deficitários, bem como se apresentem taxas baixas de resolução de conflitos mediados pela justiça ou normas legais (Santos, 1993), o caso específico do associativismo de pessoas deficientes ilustra a condição de fragilidade frente às possibilidades de mobilização cidadã dessa parcela da sociedade. Foi assim que, em pesquisa que analisou quantitativa e qualitativamente a participação de duas federações de entidades de deficientes na arena de discussões sobre a moralidade do aborto por anomalia fetal, concluiu-se que as mesmas têm-se mantido ausentes do debate, estando passivas quanto à contestação ética enfaticamente denunciada pela comunidade de deficientes da sociedade norteamericana ${ }^{7}$.

A presença insignificante de vozes de autoridade dessas entidades, no espaço que a mídia ofereceu para debater a questão, deve ser apreciada a partir da consideração de que isto se dava justamente no momento em que as mesmas entidades apregoavam e se mobilizavam pelos ideais de inclusão social da deficiência. Deve ser apreciada, ainda, a partir da consideração de que

"Os Novos Movimentos Sociais (...) usam a mídia e as atividades de protesto para mobilizar a opinião pública a seu favor. (...) Criar fatos novos que gerem impactos e virem notícia na mídia é uma preocupação permanente da maioria dos movimentos sociais" (Ghon, 2002, p. 238).

Entretanto, segundo relatórios de pesquisas realizadas pela Agência e Notícias dos Direitos da Infância, o tema da deficiência tem recebido cobertura jornalística muito pouco significativa (ANDI, 2000). Tendo em vista que as pautas jornalísticas surgem, em grande medida, a partir de demandas 
geradas por fontes do poder público e da sociedade civil, a omissão, por parte da comunidade de deficientes, parece responsável pela fraca difusão de questões acerca da deficiência.

Assim, não obstante as considerações generalistas que isentam as entidades de deficientes de exclusividade no cenário de cultura cívica concorrente com os ideais de transformação da ordem, o que se tem, diante do exposto até aqui, é que, a despeito de todo um discurso politizado presente em seus documentos oficiais, essas entidades pouco investem em mobilizações que consolidariam os fundamentos ideológicos de um novo movimento social.

\section{Conclusão}

Asch, em "Diagnóstico Pré-Natal e Aborto Seletivo", se valeu, para o cerne de sua argumentação, da aplicação do modelo social da deficiência, a qual relativiza a condição de deficiente, na medida em que a aprecia de maneira relacional com o ambiente social. Caberia, entretanto, aplicar um mesmo parâmetro relativizador que estendesse a descrição da defíciência à compreensão dos fenômenos institucionais organizados que surgem em torno dela, forjados em distintas conjunturas de sociedade civil. Caberia, ainda, nesse mesmo sentido, a compreensão dos pressupostos ideológicos e sóciohistóricos que remetem o aborto seletivo a outras práticas similarmente julgadas discriminatórias e temerárias, que, a despeito de denominação unívoca como eugênicas, distinguiram-se em suas manifestações locais.

Desse modo, o ímpeto com o qual a autora condena o aborto seletivo talvez esteja fundado numa perspectiva própria da militância estadunidense de contestação às formas de eugenia tipicamente excludentes e segregacionistas. Talvez esteja fundado ainda num contexto de mobilização da sociedade civil organizada, que permitiu a consolidação de movimentos representativos dos interesses de pessoas deficientes, os quais, já tendo inclusive alcançado sucessos nos pleitos por garantias básicas e direitos fundamentais, se encontram no ponto de sofisticarem suas exigências. Por fim, há que se dizer que tal esforço de relativização alerta para o fato de que ideologias científicas e sociais ligam-se a padrões culturais e historicamente específicos que, ao serem contextualizados, lançam luzes sobre as possíveis motivações de manifestos éticos e prescrições regulamentadoras. 


\section{Referências Bibliográficas}

ADAMS, M.A. The wellborn science: eugenics in Germany, France, Brazil and Russia. New York: Oxford University Press, 1990.

BARROS, A . Direitos reprodutivos versus direitos dos deficientes no contexto brasileiro: o retrato da mídia. In: SEMINÁRIO NACIONAL DE ANTROPOLOGIA DA SAÚDE. 1. JORNADA PARANAENSE DE ANTROPOLOGIA DA SAÚDE. 3., 2002, Curitiba. Anais... Curitiba, 2002. BARROS, A. Doenças genéticas, aborto seletivo e o movimento de pessoas deficientes. In: CONFERÊNCIA INTERNACIONAL DA FAB (FEMINIST APPROACH ON BIOETHICS). 4., Brasília, Anais... Brasília: FAB, 2002. BUCHANAN, A. Choosing who will be disabled: genetic intervention and the morality of inclusion. Social Philosophy and Policy, v. 13, n. 7, p. 1845, 1996.

FIELD, M. Killing the handicapped: before and after birth. Harvard Women's Law Journal, v. 16, p. 79-138, 1993.

GHON, M. G. Teoria dos movimentos sociais: paradigmas clássicos e contemporâneos. São Paulo: Loyola, 2002.

HARRIS, J. Is there a coherent social conception of disability? Journal of Medical Ethics. London, v. 26, n. 2, p. 95-100, 2000.

KAPLAN, D. Prenatal screening and its impact on persons with disabilities. In: ROTHENBERG, K. H.; THOMSON, E. J. (Org.). Women and prenatal testing: facing the challenges of genetic technology. Columbus: Ohio State Press, 1994.

SANTOS, W. G. Fronteiras do Estado mínimo: indicações sobre o híbrido institucional brasileiro. In: Rocco, 1993.

SAXTON, M. Why members of the disability community oppose prenatal diagnosis and selective abortion. In: PARENS, E., ASCH, A. (Org.). Prenatal testing and disability rights. Washington: Georgetown University Press, 2000.

SCHERER-WARREN, I. Redes e sociedade civil global. In: HADDAD, S. (Org.). ONGs e universidades: desafios para a cooperação na América Latina. São Paulo: Abong, 2002.

SCHIAVO, M. R. (Coord.). Perfil das percepções sobre as pessoas com síndrome de Down e do seu atendimento: aspectos qualitativos e quantitativos. Brasília: Federação Brasileira das Associações de Síndrome de Down, 1999. 
SINGER, P. Ética prática. São Paulo: Martins Fontes, 1998.

STEPAN, N. L. Eugenics in Brazil 1917-1940. In: ADAMS, M.A. The wellborn science: eugenics in Germany, France, Brazil and Russia. New York: Oxford University Press, 1990.

STEPAN, N. L. The hour of eugenics: race, gender and nation in Latin America. London: Cornell University Press, 1991.

TEIXEIRA, E. Participação cidadã no poder local: algumas experiências no Brasil. In: $O$ local e o global: limites e desafios da participação cidadã. São Paulo: Cortez/UFBA, 2001.

VIVOT, A. R. Considerações sobre a situação organizacional de entidades representativas de pessoas portadoras de deficiência. Brasília: CORDE, 1994.

\section{NOTAS}

1 Bióloga, sanitarista, doutoranda em Ciências Sociais pela Universidade Federal da Bahia. Pesquisadora do Núcleo de Estudos em Ciências Sociais, Ambiente e Saúde (ECSAS), Faculdade de Filosofia e Ciências HumanasBióloga.

2 Para conhecimento das críticas oferecidas ao modelo social de apreensão da defíciência, podese buscar o filósofo utilitarista John Harris (Harris, 2000).

3 “(...) Como os nazistas praticaram a eugenia, na Alemanha atual tudo o que tenha qualquer ligação com a engenharia genética passa a ter a mancha com as associações com o nazismo. Esse ataque inclui a rejeição do diagnóstico pré-natal, quando este é seguido pelo aborto seletivo de fetos com a síndrome de Down, espinha bífida ou outras deficiências e chega, inclusive, a rejeitar o aconselhamento genético com a finalidade de evitar a concepção de crianças portadoras de distúrbios genéticos ..." (SINGER,1998, p. 371-372).

4 Os conselhos setoriais são espaços de interlocução entre o Estado e a sociedade civil, espaços de co-gestão controle social e proposição de políticas do interesse de setores populares e excluídos. Neste sentido, segundo Scherer-Warren, “... as redes dos novos movimentos sociais foram fundamentais para a constituição de vários conselhos setoriais (da mulher, crianças e adolescentes, etc.)..." (Scherer-Warren, 2002, p. 84).

5 Segundo Vivot, “(...) as pessoas portadoras de deficiências não estão propensas, na sua maioria, à mobilização pela formação própria do paternalismo (...)” (Vivot, 1994, p. 30).

6 Em pesquisa realizada a partir de um universo composto por Associações de Síndrome de Down, por APAEs e por unidades Pestalozzi, há referência a este aspecto: “(...) Dos 211 profissionais que reportaram ter concluído um curso superior e/ou pós-superior e responderam à questão, $113(53,5 \%)$ tiveram formação na área de Educação; outros 89 ( 42,2\%) na área de saúde; cinco profissionais formaram-se em Serviço Social e os quatro restantes em outra área. ... Entre os que obtiveram formação em Saúde, os campos mais referidos - pela ordem - foram Fonoaudiologia, Psicologia, Fisioterapia e Terapia Ocupacional (...)" (Federação 
Alessandra Barros

Brasileira das Associações de Síndrome de Down, 1999, p. 97- 98).

7 Resultados desta pesquisa foram apresentados em dois momentos: em parte, em Barros (2002a), bem como em Barros (2002b).

\section{ABSTRACT}

The Limits to Indictment for Selective Abortion: Gaps in the Context of Peripheral Countries

The article analyzes the opinion presented by Adrienne Asch in "Prenatal Diagnosis and Selective Abortion" in this issue of Physis. We begin by discussing the author's position on the discriminatory nature of selective abortion, based on the quality of her argumentative rhetoric. We then proceed to review her position in light of Brazil's socio-cultural reality as a peripheral country which is characterized (as compared to the United States) as having restrictive legislation in relation to abortion, incipient organized political mobilization by people with disabilities, and a distinct history of eugenic doctrines and practices.

Keywords: Selective abortion; disability; prenatal diagnosis.

Recebido em: 29/09/2003.

Aprovado: 14/10/2003. 